\title{
むだ時間システムの外乱抑制と目標值追従性を 改善する一般化予測制御の構成方法*
}

\author{
中本 政志** - 小久保 隆*** ·清水 佳子** · 舟城 純子****
}

\author{
Two-Degree of Freedom Configulation of Generalized Predictive \\ Control to Increase the Ability of the Disturbance Rejection \\ and the Setpoint Tracking for a Dead Time System*
}

\begin{abstract}
Masashi NAKAmoto**, Takashi KoKUBo***, Keiko Shimizu** and Jyunko FunaKI****
\end{abstract}
This paper presents a two-degree freedom configuration of Generalized Predictive Control in order to increase the ability of the disturbance rejection and the setpoint tracking for a dead time system. The controller which is designed with the plant model including the feedforward control can prevent the undesirable action which is caused by the feedforward control. Numerical and experimental results demonstrate the effectiveness and the practicableness.

\section{1.はじめに}

むだ時間をもつシステムは流体を取り扱うプロセス制 御に数多くあり,フィードバック制御が難しい対象であ る. 一般化予測制御 $\left.(\mathrm{GPC})^{1}\right)$ は制御対象の出力変化を予 測して操作量を決定するので，むだ時間をもつシステム の制御に適していると考えられる.

本論文ではむだ時間をもつシステムに対して外乱除去 性能および目標値に対する追従性能を向上させる一般化 予測制御の制御構成を提案する。さらに実機試験により 提案する制御構成の効果を示す.

むだ時間をもつシステムでは，フィードバック制御だ けでは操作量の効果がむだ時間分あらわれないため，外 乱による出力の変動を十分に抑えることができない.

通常の GPC の設計では外乱は観測できないものとし

* 原稿受付 1996 年 7 月 18 日

** (株) 東芝重電技術研究所 Control Systems Department, Heavy Apparatus Engineering Laboratory, Toshiba Corporation; 2-4 Suehira-cho, Tsurumi-ku, Yokohama 230, JAPAN

*** 東京電力 (株) エネルギー・環境研究所 Energy Conversion Department, Energy and Environment R\& D Center, Tokyo Electric Power Company; 4-1 Egasaki-cho, Tsurumi-ku, Yokohama 230, JAPAN

**** (株) 東芝火力制御システム技術部 Control and Instrumentation Engineering Department, Thermal Power, Toshiba Corporation; Tsurumi-ku, Yokohama 230, JAPAN

Key Words: process control, GPC, dead time system, feedforward control, two-degree of freedom configuration.
て取り扱われるが，外乱についての情報が利用できる場 合には，観測できる外乱項をもつ予測モデルを用いて制 御則を導くことで，外乱に対する制御性の向上が図られ ると考えられる。しかし，外乱除去を効果的に行うため には，外乱発生から遅れなく操作量が作られることが必 要である. GPC で設計したコントローラの次数は制御 対象の次数に対応するが，むだ時間が長い場合にサンプ リング周期を短くすると, 制御対象の次数が大きくなり, これに伴いコントローラの次数も高くなる。これは制御 装置の計算負荷を大きくするため好ましくない.

このため, 観測される外乱を短いサンプリング周期で フィードフォワード制御として用いて, 長いサンプリン グ周期で動作する GPC と組み合わせる方法が提案され ている2).この方法では GPC はフィードフォワードと無 関係に求められるため, 望ましくない応答を示すことが ある。

本論文では,フィードフォワード制御を行ったシステ ムに対して予測モデルを構成して GPC を設計すること で,さらに外乱除去の効果が改善されることを示す.

また目標値に対する追従性は, 制御系を 2 自由度系と することで向上できることが知られている．このとき， 目標值からの直達分と, フィードバックループの積分器 出力が二重に加えられ, 目標值に対するオーバシュート が大きくなることがある. 最適レギュレータではこれら を考慮した設計法が提案されている3),4)。この論文では 外乱についてのフィードフォワード制御と同様な予測モ 
デルの構成により，オーバシュートをさける方法を提案 する.

論文の構成は以下のとおりである．2. では外乱からの フィードフォワードをもつシステムに対する GPC の設 計について述べる. 3. では目標值からの 2 自由度構成と したシステムに対する GPC の構成について述べる. 4. はシミュレーションにより提案する制御構成の効果を示 す. 5. では実プラントでの試験結果を紹介する.

\section{GPC を用いた外乱除去}

\section{1 制御対象}

検討するプラントの構成を Fig. 1 に示す. $G_{1}(s)$, $G_{2}(s)$ は 1 入力 1 出力のシステムでむだ時間を持つも のとする. また $G_{2}(s)$ は安定とする $y, u, d, \xi$ はそ れぞれプラント出力, 制御入力, 観測可能な外乱, 観測 できない外乱とする。このような制御対象として, 熱交 換器などのような大きなむだ時間と時定数をもつ $G_{1}(s)$ の出力を, 弁などの比較的短い遅れをもつ $G_{2}(s)$ を介し て制御するものがある。

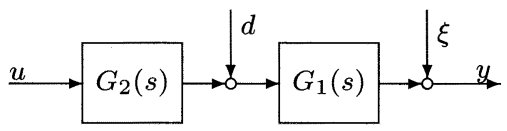

Fig. 1 Plant 1

外乱 $d$ が変化したとき Fig. 1 のプラント出力の変動は, $G_{1}(s)$ のむだ時間分は観測されない.このため, 仮に理 想的なフィードバック制御が実現できたとしても，フィー ドバック制御だけではむだ時間分の外乱の影響は打ち消 すことができない.一方 $G_{2}(s)$ の遅れが小さい場合には， 外乱情報から直接操作量を作ることで, 外乱除去の効果 を改善できることが期待できる。

$P_{1}(s)=G_{1}(s) G_{2}(s), P_{2}(s)=G_{1}(s)$ とおくと, Fig. 2 のシステムはFig. 1 と等価になる．以下では一般性の点 からプラントの構成を Fig. 2 とする.このとき制御対象 は(1) 式となる.

$$
y=P_{1} u+P_{2} d+\xi
$$

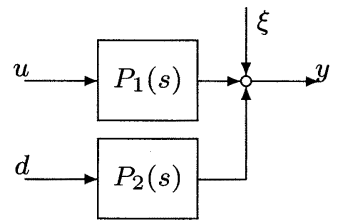

Fig. 2 Plant 2

\section{2 制御構成}

制御構成として次の四つが考えられる。

(1) 外乱補償を行わない (Fig. 3)

(2) 観測可能な外乱を含む予測モデルを用いた GPC (Fig. 4)

(3) 外乱からのフィードフォワードを行う (Fig. 5)

(4) フィードフォワードと外乱を考慮した予測モデル を用いた GPC (Fig. 6)

以下では (2), (4) について検討する.

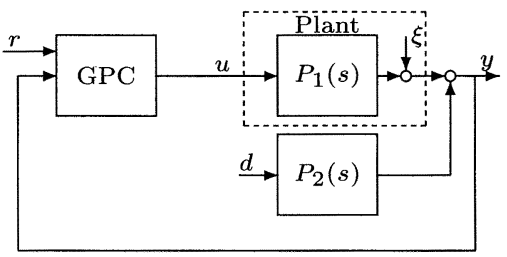

Fig. 3 Conventional GPC control

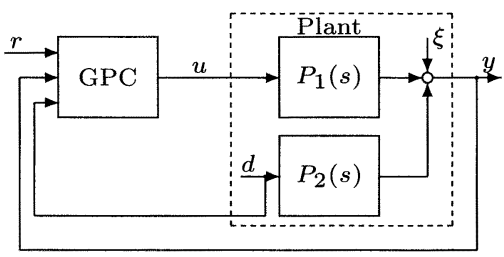

Fig. 4 GPC design with a disturbance signal

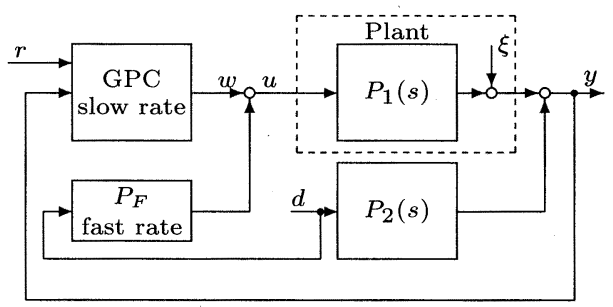

Fig. 5 GPC with a feedforward control

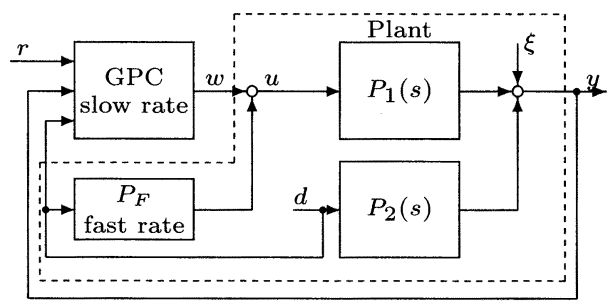

Fig. 6 GPC design with a feedforward model 


\subsection{1観測可能な外乱を含む予測モデルを用いた GPC}

通常の GPC では外乱信号を用いないが，ここでは観 測できる外乱を利用できるように GPC を変形する。こ れは予測モデルに外乱項を含ませることで容易にできる.

Fig. 2 に示す制御対象を (2) 式の離散時間モデルの形 に書く.

$$
\begin{aligned}
A\left(z^{-1}\right) y(t)= & B_{1}\left(z^{-1}\right) u(t-1) \\
& +B_{2}\left(z^{-1}\right) d(t-1)+\frac{v(t)}{\Delta}
\end{aligned}
$$

ここで $v(t)$ は $\xi$ の離散時間表現とする。また $\Delta=1$ $z^{-1}$ とする. $E_{j}\left(z^{-1}\right), F_{j}\left(z^{-1}\right), G_{j}\left(z^{-1}\right), H_{j}\left(z^{-1}\right)$, $K_{j}\left(z^{-1}\right), L_{j}\left(z^{-1}\right)$ を以下の Diophantine 方程式を满た す $z^{-1}$ の多項式とする.

$$
\begin{aligned}
& 1=E_{j}\left(z^{-1}\right) A\left(z^{-1}\right) \Delta+z^{-j} F_{j}\left(z^{-1}\right) \\
& E_{j}\left(z^{-1}\right) B_{1}\left(z^{-1}\right)=G_{j}\left(z^{-1}\right)+z^{-j} H_{j}\left(z^{-1}\right) \\
& E_{j}\left(z^{-1}\right) B_{2}\left(z^{-1}\right)=K_{j}\left(z^{-1}\right)+z^{-j} L_{j}\left(z^{-1}\right)
\end{aligned}
$$

これから (2) 式に対する最適な予測モデルは次式となる.

$$
\begin{aligned}
\hat{y}(t+j)= & F_{j}\left(z^{-1}\right) y(t)+G_{j}\left(z^{-1}\right) \Delta u(t+j-1) \\
& +H_{j}\left(z^{-1}\right) \Delta u(t-1)+L_{j}\left(z^{-1}\right) \Delta d(t-1) \\
& +K_{j}\left(z^{-1}\right) \Delta d(t+j-1)
\end{aligned}
$$

ここで $\hat{y}(t+j)$ は $y(t)$ の $j$ ステップ先の予測值とする. $r(t+j)$ を $j$ ステップ先の目標值とすると, 次の評価関数

$$
J=\sum_{j=1}^{N_{P}}\left\{(\hat{y}(t+j)-r(t+j))^{2}+\lambda \Delta u(t+j-1)^{2}\right\}
$$

を最小にする操作量の変化分 $\Delta u(t+j-1), j=1, \cdots, N_{P}$ は, $\partial J / \partial \Delta \hat{u}=0$ より1),

$$
\begin{aligned}
\Delta \hat{u}= & -\left(\lambda I+G^{\mathrm{T}} G\right)^{-1} G^{\mathrm{T}} \\
& (F y+H \Delta u+K \Delta \hat{d}+L \Delta d-\hat{r})
\end{aligned}
$$

となる。制御には $\Delta \hat{u}$ の一番目の要素を用いる。ここ で $y=[y(t) \cdots y(t-n)]^{\mathrm{T}}, \hat{u}=\left[u(t) \cdots u\left(t+N_{P}-1\right)\right]^{\mathrm{T}}$, $u=[u(t-1) \cdots u(t-m)]^{\mathrm{T}}, \hat{d}=\left[d(t) \cdots d\left(t+N_{P}-1\right)\right]^{\mathrm{T}}$, $d=[d(t-1) \cdots d(t-l)], \hat{r}=\left[r(t) \cdots r\left(t+N_{P}-1\right)\right]^{\mathrm{T}}$ であ る. $n, m, l$ はそれぞれ $A\left(z^{-1}\right), B_{1}\left(z^{-1}\right), B_{2}\left(z^{-1}\right)$ の次数である.また $G, K$ は $N_{P} \times N_{P}$ の下三角の行 列で $(i, k)$ 要素が多項式 $G_{j}, K_{j}$ の $z^{-(i-k)}$ 次の係数 である. $F, H, L$ はそれぞれ $N_{P} \times(n+1), N_{P} \times m$, $N_{P} \times l$ の行列で多項式 $F_{j}, H_{j}, L_{j}$ の $z^{-(k-1)}$ 次の係 数を $(j, k)$ 要素とする行列である.

\subsection{2 フィードフォワードと外乱を考慮した予測モデ ルを用いた GPC による外乱除去}

むだ時間のあるプラントで外乱除去を行うには，短い サンプリング周期で外乱からのフィードフォワードを設 けることが効果的である。ただしサプリング周期を短 くすることは制御装置の実装の点から好ましくない.こ のため Fig. 5 に示すように, フィードフォワードと GPC について別々のサンプリング周期を持つようコントロー ラを構成する方法が提案されている2). ただしこの方法 では GPC とフィードフォワードとが独立に設計されてい るため, 外乱に対するフィードフォワードの動作が GPC には反映されない. そのため数值例に示すように, フィー ドフォワードでは過渡的に除去できない外乱の出力への 影響を,フィードバックにより消そうとして不要な操作 信号を発生し出力が変動する。

これを解決するため GPC の設計のための対象プラン トをフィードフォワードを行ったシステムとする．外乱 からのゲインを $P_{F}$ とおくと (1) 式の $P_{2} を P_{2}+P_{1} P_{F}$ とおくことで (2) 式以降と同様に設計を行うことができ る.この場合 GPC のサンプリング周期に比ベフィード フォワードのサンプリング周期は十分早く, フィードフォ ワード制御は連続時間で行われているとみなす，全体の 制御構成はFig. 6 に示すようになる。

\section{2 自由度構成による目標值追従性の改善}

将来のプラント出力の目標值が利用できる場合には (7) 式に示すように操作量を先行的につくることができるが, ここでは将来の目標值が事前にはわからない場合の目標 值に対する追従性を改良するため, 目標值から直接操作 量を作る 2 自由度構成を検討する. 以下では制御対象は,

$$
y=P_{1} u+\xi
$$

とする．また $P_{1}$ は安定とする. 2 自由度構成の操作量 を $u=w+P_{S} r$ とする. ゲイン $P_{S}$ は $P_{1}$ の定常ゲイン の逆数 $1 / P_{1}(0)$ が用いられることが多い.このとき外乱 やモデル化誤差がなければ, 十分時間がたてばフィード バックがなくても, すなわち $w=0$ でも, プラント出力 は目標値に一致する。

このような 2 自由度構成で操作量をつくると, 制御量 が目標值に一致するまでの間, 目標值と制御量との偏差 を積分器で積分し操作量に加算するため, 操作量が必要 な值以上に変化しプラント出力にオーバシュートを生じ ることがある。

ここでは設計のためのプラントモデルを修正すること でオーバシュートのない GPC の構成を求める. (8) 式に 2 自由度構成の操作量 $u=w+P_{S} r$ が入力されたプラン 
トを考える。

$$
\begin{aligned}
y & =P_{1} u+\xi \\
& =P_{1}\left(w+P_{S} r\right)+\xi \\
& =P_{1} w+P_{1} P_{S} r+\xi
\end{aligned}
$$

ここで $r$ を一種の外乱とみなし,$P_{2}=P_{1} P_{S}$ とおいて

2.2.1 により GPC を設計する.

\section{4. 数值例}

\section{1 外乱除去特性}

実機試験のプラントを対象としてシミュレーションを 行う. 制御対象のモデルは,

$$
G_{1}(s)=\frac{e^{-L_{1} s}}{\left(1+T_{1} s\right)^{2}}, \quad G_{2}(s)=\frac{e^{-L_{2} s}}{1+T_{2} s}
$$

となり，

$$
T_{1}=15, \quad L_{1}=110, \quad T_{2}=5, \quad L_{2}=10
$$

である。このとき，外乱に対する補償の方法による次の 四つの設計を比較する。

(1) 外乱補償を行わない

制御対象のモデルを $y=P_{1} u+\xi$ として GPC を 設計する。

(2) 外乱を考慮した予測モデルを用いる

2.2.1 で説明した方法で GPC を設計する。この とき制御対象は $y=P_{1} u+P_{2} d+\xi$ となる.

(3) フィードフォワードによる外乱除去

参考文献 2) の方法による．GPC の設計モデルは $y=P_{1} u+\xi$ である.フィードフォワードのゲイン は $P_{F}=-1 / G_{2}(0)$ とする.

(4) フィードフォワードと外乱予測モデルを用いた $\mathrm{GPC}$ による外乱除去

2.2.2 で説明した方法でフィードフォワードと組 み合わせて GPC を設計する.フィードフォワ ードのゲインは上と同様 $P_{F}=-1 / G_{2}(0)$ とす る。これから $\mathrm{GPC} の$ 設計のための制御対象は $y=P_{1} w+\left(P_{2}-P_{1} / G_{2}(0)\right) d+\xi$ となる.

時刻 0 で大きさ 1 の外乱をステップで加えた計算を行う. 結果を Fig. 7 に示す. GPC はサンプリング周期 5 秒, 予 測長 40 サンプル，操作量への重み $\lambda=5$ としてゲインを 求めた。

外乱補償を行わない制御構成では, むだ時間分は外乱 による出力の変動を補償できないため, 出力に大きな変 動を生じる: 外乱を予測モデルに入れて設計することで, 外乱の影響を早く補償できる.フィードフォワードの方 法は外乱による出力への影響がさらに小さくなるが，逆

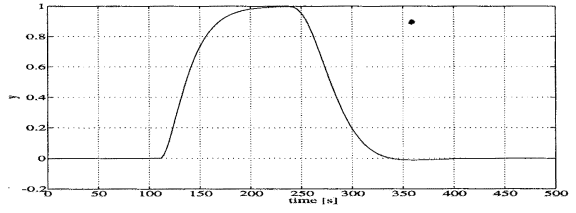

(a) Conventional GPC design

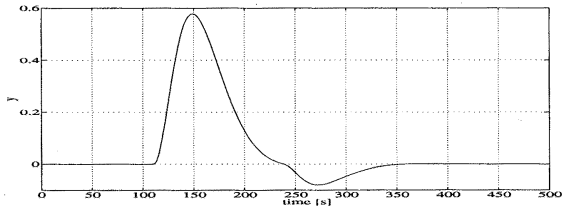

(b) GPC design with disturbance signal

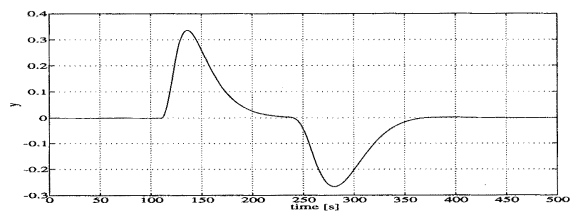

(c) GPC with a feedforward control

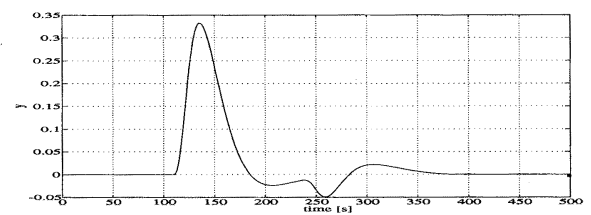

(d) GPC design with a feedforward model

Fig. 7 Simulation results for a disturbance rejection

応答が生じる。フィードフォワードを考慮した予測モデ ルを用いる方法では，この逆応答が抑えられる。

\section{2 目標值追従性}

上と同じ制御対象についてシミュレーションを行う. 次 の三つの設計方法について比較する.

(1) 1 自由度構成

制御対象のモデルを $y=P_{1} u+\xi$ として GPC を 設計する。

(2) 2 自由度構成

フィードフォワードゲインは $P_{1}(0)=1$ なので $P_{S}=1$ となる. GPC は上と同様に求める. 操作 量は $u=w+r$ となる.

(3) 2 自由度構成を考慮した予測モデルによる GPCに よる設計 
設計モデルは 2 自由度構成を考慮して $y=P_{1} w+$

$P_{1} r+\xi$ とする. 操作量は $u=w+r$ となる.

時刻 0 で目標值を大きさ1 ステップで変化したときの計 算結果を Fig. 8 に示す. GPC のゲインはサンプリング 周期 20 秒, 予測長 10 サンプル, 操作量への重み $\lambda=5$ として計算した. Fig. 8(a), (b) に比べ, Fig. 8(c) に示 すように 2 自由度構成を考慮した予測モデルを用いるこ とで, 目標值への追従性が早くオーバシュートのない制 御系が構成される。

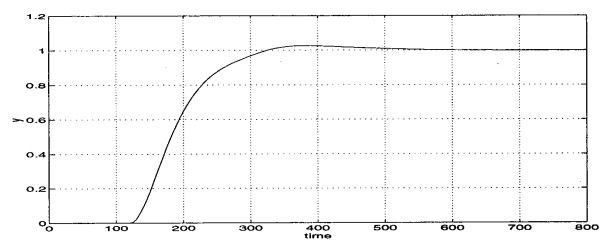

(a) Conventional GPC design

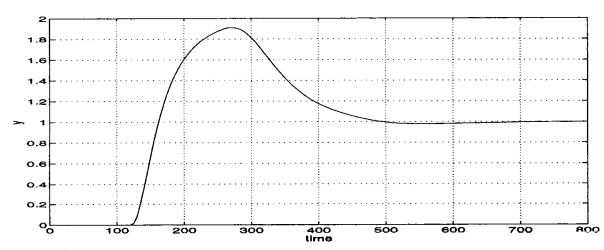

(b) GPC with two-degree of freedom configuration

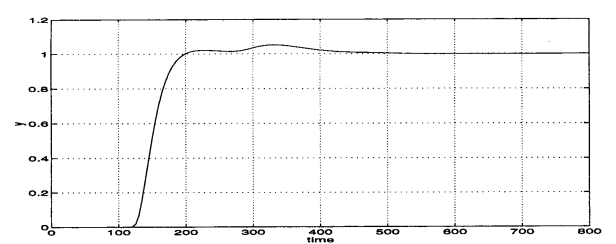

(c) GPC with two-degree of freedom configuration model

Fig. 8 Simulation results for a setpoint change

\section{5. 試験}

\section{1 プラント}

これまで検討した方法を用いて実機プラントで試験を 行い効果を評価する.プラントの全体構成を Fig. 9 に示 す.ここで対象とする制御プロセスはガスタービン（gas turbine), 排熱回収ボイラ (HRSG), 蒸気タービン等で 構成されるコンバインドサイクル発電プラントの脱硝制 御である.ガスタービンは天然ガス等を燃料として使用 するが, 燃焼に伴って窒素酸化物 $(\mathrm{NOx})$ が発生する.

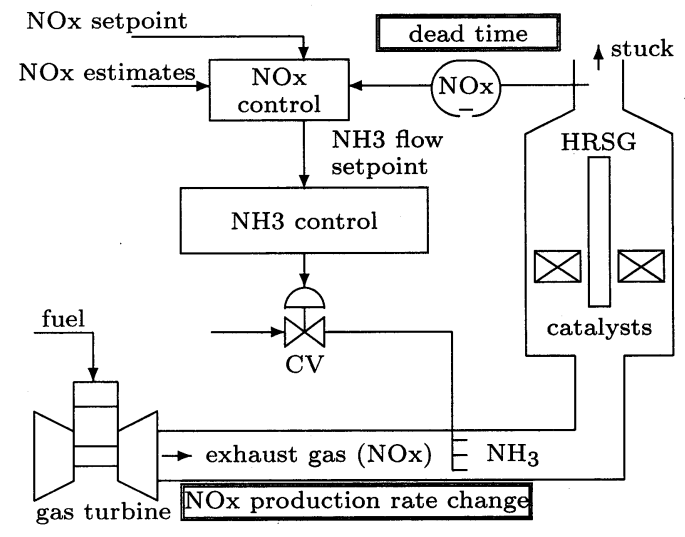

Fig. 9 Combined cycle power plant

この NOx を低減するために燃焼排気ガス中にアンモニ ア $\left(\mathrm{NH}_{3}\right)$ を注入して排熱回収ボイラ内に設けられた脱 硝触媒で窒素と水に分解する.未反応の $\mathrm{NOx}$ の濃度は HRSG 出口に設けたガス分析計で計測される. NOx の 流量はガス流量と濃度の積として求められる.

脱硝制御系の目的は発電プラントから排出される NOx 量をある定められた值に保つことである．脱硝制御全体 は $\mathrm{NOx}$ 制御と $\mathrm{NH}_{3}$ 制御系から構成されている. $\mathrm{NH}_{3}$ 制御系は $\mathrm{NOx}$ 制御系に比べて応答が早いため,ここで は制御対象の一部とみなす. 制御対象は Fig. 1 に示す構 成を持ち, 出力は未反応の $\mathrm{NOx}$ 量, 外乱はガスタービ ンで発生する $\mathrm{NOx}$ 量, 入力は $\mathrm{NH}_{3}$ の流量指令值であ る.プラントの動特性パラメータは 4. で説明した值を もつ.

脱硝制御系の特徴として次のようなことがあげられる.

(1) ガス中の NOx 濃度の検出のため 2 分程度のむだ 時間がある。

(2) NOx の発生量はガスタービンの運転状態により 変動する。この発生量は推定できるが誤差がある。

\section{2 外乱除去特性}

ガスタービンの運転状態を変化させて発生する NOx 量を変えた試験を行った. Fig. 10 に 4 (3) の方法, Fig. 11 に (4) の方法による試験結果を示す. 各図の (b) で変化幅の大きいほうが操作量である．数值例と同様に， フィードフォワードを考慮した予測モデルを用いること で逆応答なく外乱変動が抑えられる.フィードフォワー ドを行わない方法はプラント出力の変動が過大になる恐 れがあるため, 試験は実施しなかった. 


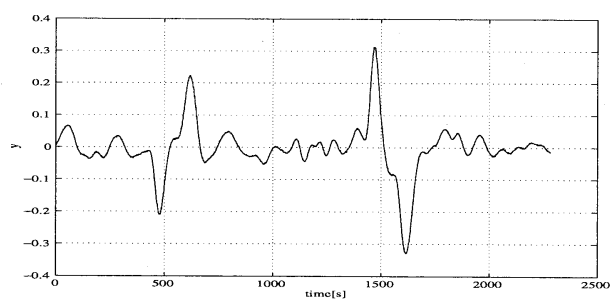

(a) Plant output

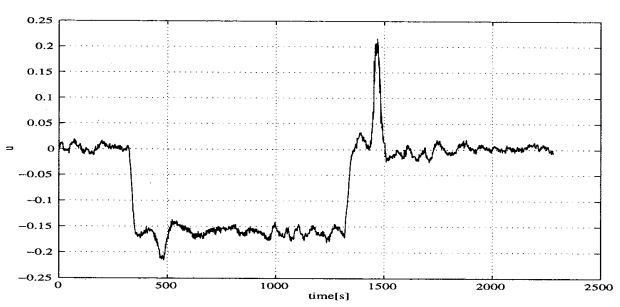

(b) Manipulated value

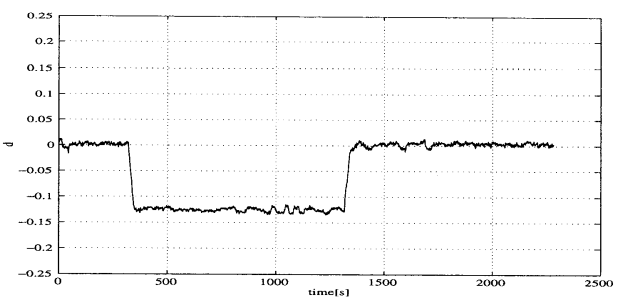

(c) Disturbance value

Fig. 10 GPC with a feedforward control

\section{3. 目標值追従性}

目標値をステップで変化させた試験を行った。 1 自由度 構成の結果を Fig. 12，2 自由度構成の結果を Fig. 13，2 自由度構成を考慮した予測モデルによる GPC の結果を Fig. 14 に示す. 設計は数值例と同じ条件で行った. 数值 例と同様に 2 自由度構成を考慮した予測モデルを用いて GPC を設計することで; 目標值への追従性が早くオー バシュートのない制御系が得られた.

\section{4 考察}

ここで用いた方法はフィードフォワードを用いている が, フィードフォワード制御はロバストでないので, モ デル化誤差や運転点の変更によるプラント特性の変化が 出力にそのまま影響を与える. Fig. 14 に見られるよう に, 操作量の最初の変化では出力が目標値に達していな いのはこのためである.

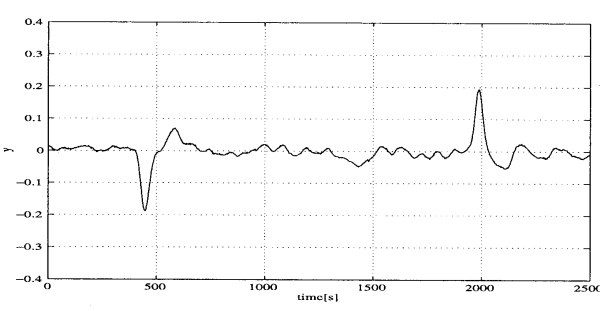

(a) Plant output

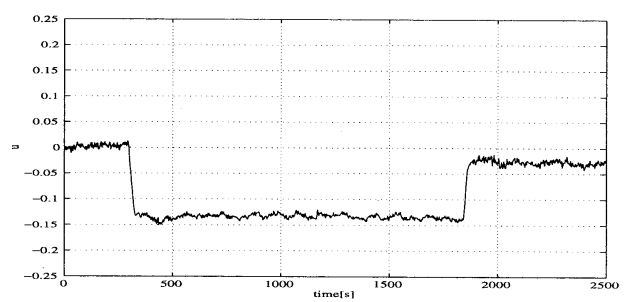

(b) Manipulated value

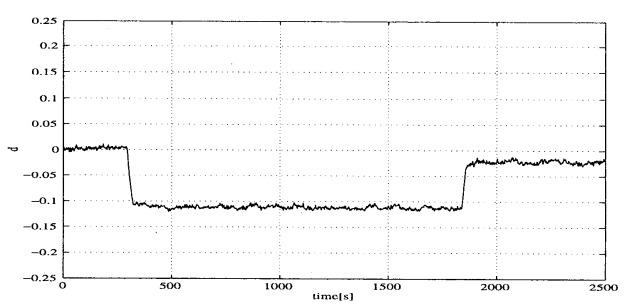

(c) Disturbance value

Fig. 11 GPC design with a feedforward model

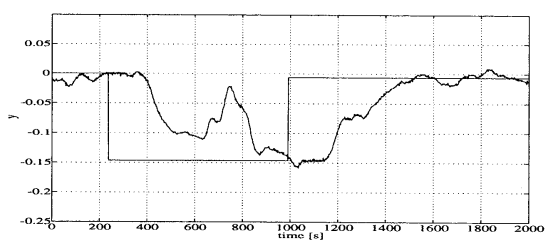

(a) Plant output

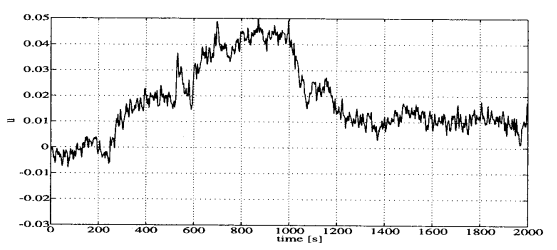

(b) Manipulated value

Fig. 12 One-degree of freedom configuration 


\section{参 考文 献}

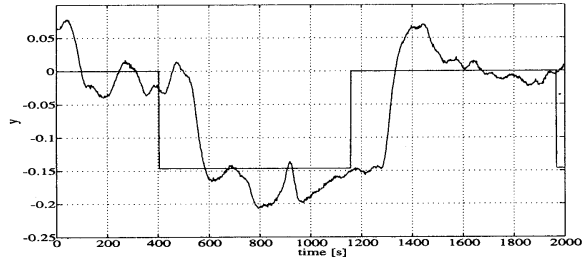

(a) Plant output

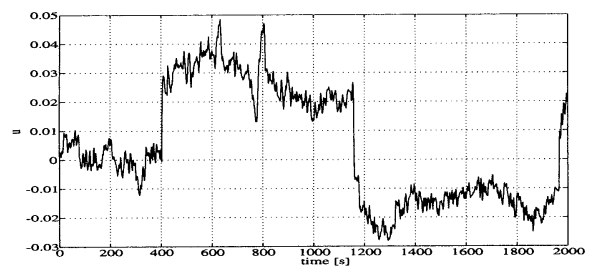

(b) Manipulated value

Fig. 13 Two-degree of freedom configuration

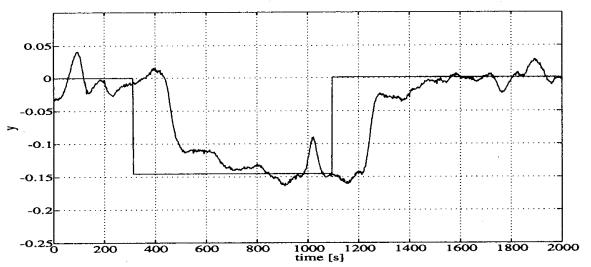

(a) Plant output

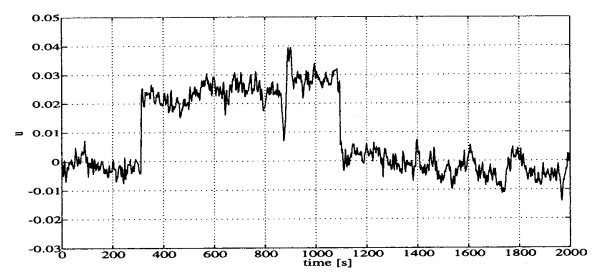

(b) Manipulated value

Fig. 14 GPC with two-degree of freedom configuration model

\section{6. おわりに}

本研究では GPC を用いたむだ時間システムの制御に おいて，外乱除去特性の向上と目標值追従性の改善をは かる制御設計方法について提案した. 得られた設計方法 を用いて実機試験を行い制御性の改善を示した。
1) R. R. Bitmead, M. Gevers and V. Wertz: Adaptive Optimal Control - The Thinking Man's GPC, Prentice-Hall (1991)

2) 清水, 中本, 小久保, 田辺：一般化予測制御による火力発電 プラントの脱硝プロセスの制御; 計測自動制御学会論文集, Vol. 32, No. 6, pp. 912-920 (1996)

3) 池田, 須田：積分型最適サーボ系の 2 自由度構成；第 31 回 自動制御連合講演会前刷, pp. 115-116 (1988)

4) 藤崎, 池田: 2 自由度積分型最適サーボ系の構成; 計測自動 制御学会論文集, Vol. 27, No. 8, pp. 907-914 (1991) 